\title{
EQUILIBRIUM MODELING OF MONO AND BINARY SORPTION OF CU(II) AND ZN(II) ONTO CHITOSAN GEL BEADS
}

\author{
Józef Nastaj*, Małgorzata Tuligłowicz, Konrad Witkiewicz \\ West Pomeranian University of Technology, Department of Chemical Engineering and \\ Environmental Protection Processes, Szczecin, al. Piastów 42, 71-065 Szczecin, Poland
}

\begin{abstract}
The objective of the work are in-depth experimental studies of $\mathrm{Cu}(\mathrm{II})$ and $\mathrm{Zn}$ (II) ion removal on chitosan gel beads from both one- and two-component water solutions at the temperature of $303 \mathrm{~K}$. The optimal process conditions such as: $\mathrm{pH}$ value, dose of sorbent and contact time were determined. Based on the optimal process conditions, equilibrium and kinetic studies were carried out. The maximum sorption capacities equaled: $191.25 \mathrm{mg} / \mathrm{g}$ and $142.88 \mathrm{mg} / \mathrm{g}$ for $\mathrm{Cu}$ (II) and $\mathrm{Zn}$ (II) ions respectively, when the sorbent dose was $10 \mathrm{~g} / \mathrm{L}$ and the $\mathrm{pH}$ of a solution was 5.0 for both heavy metal ions. One-component sorption equilibrium data were successfully presented for six of the most useful three-parameter equilibrium models: Langmuir-Freundlich, Redlich-Peterson, Sips, Koble-Corrigan, Hill and Toth. Extended forms of Langmuir-Freundlich, Koble-Corrigan and Sips models were also well fitted to the two-component equilibrium data obtained for different ratios of concentrations of $\mathrm{Cu}(\mathrm{II})$ and $\mathrm{Zn}(\mathrm{II})$ ions $(1: 1,1: 2,2: 1)$. Experimental sorption data were described by two kinetic models of the pseudo-first and pseudo-second order. Furthermore, an attempt to explain the mechanisms of the divalent metal ion sorption process on chitosan gel beads was undertaken.
\end{abstract}

Keywords: chitosan, heavy metals, equilibrium modeling, binary solutions

\section{INTRODUCTION}

In the last decade, the presence of heavy metal ions in the environment has attracted attention of researches. The amount of heavy metal release into the environment is increasing as a result of development of industrial processes and technological expansion. The potential sources of heavy metal ions are industrial wastewaters which include: fertilizers, pigments, metal finishing etc. (Arh-Hwang et al., 2008; Tomczak, 2013). Waste streams containing $\mathrm{Cu}$ (II) originated from a variety of industries among others: meishing and copper electroplating, which cause a significant threat to aquatic life and make natural water unsuitable for public use (Alimohamadi et al., 2005; Hasan et al., 2008).

$\mathrm{Zn}$ (II) can be found in wastewater derived from various electroplating pollutants e.g.: acid mine drainage (AMD), electroplating and from municipal wastewater. $\mathrm{Zn}(\mathrm{II})$ is not biodegradable and can accumulate throughout the food chain, becoming a serious danger (Norton et al., 2004). Therefore $\mathrm{Cu}$ (II) and $\mathrm{Zn}$ (II) ions are among the most common heavy metals in industries wastewaters. The accumulation of $\mathrm{Cu}(\mathrm{II})$ ions in human body causes brain, skin and pancreas damage and heart diseases. $\mathrm{Zn}(\mathrm{II})$ ions are on the list of priority pollutants giving rise to serious poisoning cases.

The heavy metals, which are detrimental to one's health, can be removed from wastewater using various conventional methods such as: precipitation, reverse osmosis, chemical reduction, ion exchange 
and physical sorption (Veli and Alyuz, 2007). However, the above processes proceed slowly and their effectiveness depends on many factors such as: the $\mathrm{pH}$ of a solution, the type of a heavy metal ions (oxidation state, type of complexes) and the concentration or the presence of other substances dissolved in water.

The biosorption process is an alternative to traditional methods of heavy metal removal from aqueous solutions. It is a biological purification method of wastewaters, based on the binding of metal ions on the biosorbent surface.

Chitosan is a low cost natural material, used for biosorption of heavy metal ions (Alimohamadi et al., 2005; Chen et al., 2008; Hasan et al., 2008; Norton et al., 2004; Sevil and Alyuz, 2007). Chitosan is a derivative of chitin, which can be extracted from fungi, and in large quantities, from the exoskeleton of crustaceans such as crabs, shrimps, krill and crawfish. In comparison with chitin, chitosan is more efficient in terms of sorption capacity. It is due to the presence of a large number of free amino groups on chitosan chain which are responsible for the high sorption capacity (Sankararamakrishnan et al., 2007). However, unlike chitin, chitosan is soluble in dilute organic acids, such as acetic or formic acids.

The most interesting fact, compared to other sorbents, is that chitosan can be processed into: flakes (Jha et al., 1987), beads (Baran et al., 2006) and membranes (Osifo et al., 2008). Chitosan can be physically and chemically modified to improve the sorption capacity and the chemical stability of chitosan in acid media (Kyzas and Bikiaris, 2015). Chitosan without modification has already high chemical stability in acid media. It is resistant to biochemical and microbiological degradation and most of all has high affinity for sorption of heavy metal ions.

Most of the studies dedicated to metal ion biosorption on various modified chitosan concern one component metal ion water solutions, although the real aquatic solutions generally consist of toxic heavy metal mixtures (Wan Ngah and Fatinathan, 2008).

Therefore the main objective of this study was to investigate the sorption process of copper $(\mathrm{Cu}(\mathrm{II}))$ and zinc ( $\mathrm{Zn}(\mathrm{II}))$ ions from one- and two-component water solutions on unmodified chitosan gel beads.

\section{SORPTION MECHANISMS}

Chitosan is a strongly complexing polymer in relation to heavy metal ions. Amino groups of chitosan chains in which nitrogen is the donor of electron pairs are responsible for the formation of such complexes (Jin and Bai, 2002; Onsosyen and Skaugrud, 1990; Rinaudo, 2006). Both nitrogen and oxygen atoms have lone pairs of electrons which can bind a proton of metal ion to form a complex (Onsoyen and Skaugrud, 1990). However, nitrogen atoms have stronger tendency to donate the lone pair of electrons with heavy metal ions to form a complex than the oxygen atom. Based on the above consideration, the process can proceed according to the following reaction (Jin and Bai, 2002):

$$
\mathrm{R}-\mathrm{NH}_{2}+\mathrm{H}^{+} \leftrightarrow \mathrm{R}-\mathrm{NH}_{3}^{+}
$$

This reaction indicates the protonation and deprotonation processes of amino groups in chitosan. The binding mechanism of the group with heavy metal ions is very specific and can depend on other factors, such as: $\mathrm{pH}$ value or type of metal ion. For example, at a lower $\mathrm{pH}$ of a solution more amino groups are protonated. Whereas at higher $\mathrm{pH}$ values, $\mathrm{OH}^{-}$ions can be adsorbed to the surface of chitosan gel beads through a hydrogen bond (Jin and Bai, 2002; Rinaudo, 2006):

$$
\mathrm{R}-\mathrm{NH}_{2}+\mathrm{OH}^{-} \rightarrow \mathrm{R}-\mathrm{NH}_{2} \cdot \cdots \mathrm{OH}^{-}
$$


When heavy metal ions were added into the solution, the reaction proceded due to sharing of the lone pair of the electrons from the nitrogen atom with heavy metal ion, in the similar manner as reaction (Sankararamakrishnan et al., 2007):

$$
\mathrm{R}-\mathrm{NH}_{2}+\mathrm{M}^{2+} \leftrightarrow \mathrm{R}-\mathrm{NH}_{2} \mathrm{M}^{2+}
$$

However, the electrical attraction force between lone pair electrons from the nitrogen atom and the bivalent heavy metal ion can be stronger than that between the lone pair of electrons from the nitrogen atom and the monovalent proton $\left(\mathrm{H}^{+}\right)$(Jin and Bai, 2002; Onsoyen and Skaugrud, 1990; Rinaudo, 2006; Wang et al., 2004). From these differences in the force of the binding we can write another reaction described as follows:

$$
\mathrm{R}-\mathrm{NH}_{3}{ }^{+}+\mathrm{M}^{2+} \leftrightarrow \mathrm{R}-\mathrm{NH}_{2} \mathrm{M}^{2+}+\mathrm{H}^{+}
$$

In this reaction a competitive adsorption of $\mathrm{M}^{2+}$ over $\mathrm{H}^{+}$to the nitrogen atom occurs, which can be considered as ion exchange mechanism (Jin and Bai, 2002; Onsosyen and Skaugrud, 1990). In comparison to reaction (3), reaction (4) can run slowly, due to smaller force attraction between the $\mathrm{N}$ in $\mathrm{R}^{-\mathrm{NH}_{3}}$ and $\mathrm{M}^{2+}$ (Oyrton et al., 1999).

For the complex of $\mathrm{R}-\mathrm{NH}_{2} \mathrm{M}^{2+}$ it is greater binding force of $\mathrm{M}^{2+}$ with the $\mathrm{OH}^{-}$group from water:

$$
\mathrm{R}-\mathrm{NH}_{2} \mathrm{M}^{2+}+\mathrm{H}_{2} \mathrm{O} \leftrightarrow \mathrm{MOH}^{+}+\mathrm{R}^{-\mathrm{NH}_{3}}{ }^{+}
$$

This reaction together with reactions (2) and (4) make heavy metal ions be present in the complex of $\mathrm{R}-\mathrm{NH}_{2} \mathrm{M}^{2+}$ rather than be distributed in the solution. Heavy metal sorption on chitosan gel beads can also be controlled by the transport of heavy metal ions from the solution bulk to the chitosan bead surface. The transport of heavy metal cation $\mathrm{M}^{2+}$ to the surface sites $\mathrm{R}-\mathrm{NH}_{3}{ }^{+}$could be inhibited at very low $\mathrm{pH}$ of solution.

\section{EXPERIMENTAL METHODS}

\subsection{Materials}

The chitosan flakes used in experiments were deacetylated approximately $85 \%$ and their dynamic viscosity $\left(20{ }^{\circ} \mathrm{C}\right)$ was $3200 \mathrm{mPa} \cdot \mathrm{s}$. The chitosan was purchased from Biolog Biotechnologie und Logistic $\mathrm{GmbH}$. Copper(II) sulfate $\left(\mathrm{CuSO}_{4}\right)$ and zinc sulfate heptahydrate $\left(\mathrm{ZnSO}_{4} \cdot 7 \mathrm{H}_{2} \mathrm{O}\right)$ used in the sorption experiments were purchased from Chempur and were of analytical grade.

\subsubsection{Preparation of chitosan gel beads}

Preparation of chitosan gel beads involves dissolving $17.5 \mathrm{~g}$ of chitosan flakes in $1 \mathrm{~L}$ of $2 \%$ aqueous solution of acetic acid and leaving the solution for $24 \mathrm{~h}$. Then the dissolved chitosan is subjected to filtration in order to remove any kind of contamination. The formation of drops involves the use of the pressure method, which consists of compressed air being brought to a container with a solution of chitosan. The chitosan solution was pressed through a capillary with a diameter of $2 \mathrm{~mm}$ finished with the blade to facilitate the formation of droplets. The diameter of chitosan gel beads was about $2.5 \mathrm{~mm}$.

Discharged drops fell freely into the cylinder with a solution of $10 \%$ sodium hydroxide. The process was conducted by applying continuous mixing.

In the final step beads were washed with distilled water to remove any residues of sodium hydroxide. Before the sorption process chitosan gel beads were kept in distilled water at least seven days. 


\subsection{Sorption studies}

\subsection{1. pH effects}

The effect of the $\mathrm{pH}$ of solutions on $\mathrm{Cu}(\mathrm{II})$ and $\mathrm{Zn}$ (II) sorption were examined by adding $10 \mathrm{~g}$ of wet chitosan beads (dry mass was related to wet one and was at a constant ratio in experiments) into 200 $\mathrm{mL}$ solutions containing $\mathrm{Cu}(\mathrm{II})$ and/or $\mathrm{Zn}$ (II) to $250 \mathrm{~mL}$ dark flasks. In one-component systems the ion initial concentration was constant and equaled $60 \mathrm{mg} / \mathrm{L}$. In two-component solutions the $\mathrm{Cu}$ (II)- $\mathrm{Zn}$ (II) mixture of concentration ratio 1:1 was used in which each ion initial concentration was also constant and equaled $64 \mathrm{mg} / \mathrm{L}$. These solutions were adjusted to $\mathrm{pH} 4.0,5.0,6.0$ and 6.5 with $0.1 \mathrm{M}$ hydrochloric acid or $0.1 \mathrm{M}$ sodium hydroxide solution. Concentrations of solutions were measured with Inductively Coupled Plasma Spectrometer ICP-AES (Jobin Yvon, France). The sorption capacity was calculated using the relation:

$$
q_{e}=\frac{C_{0}-C_{e}}{m} V
$$

\subsubsection{Effect of sorbent dose}

The dependence of metal ion sorption on the dose of chitosan gel beads was examined using various amounts of sorbent, ranging from 5 to $15 \mathrm{~g}$ wet chitosan beads into $200 \mathrm{~mL}$ solutions containing $\mathrm{Cu}(\mathrm{II})$ or $\mathrm{Zn}(\mathrm{II})$ in the concentration of $60 \mathrm{mg} / \mathrm{L}$. Thus, the sorbent dose ranged from 25 to $75 \mathrm{~g} / \mathrm{L}$. Concentrations were also measured with Inductively Coupled Plasma Spectrometer ICP-AES.

\subsubsection{Effect of contact time}

Experiments of contact time effect were carried out by placing $10 \mathrm{~g}$ of wet chitosan beads into $200 \mathrm{~mL}$ solution containing $\mathrm{Cu}(\mathrm{II})$ or $\mathrm{Zn}(\mathrm{II})$ ions, with a sorbent dose of $50 \mathrm{~g} / \mathrm{L}$. Samples were stirred in an incubator shaker at a constant value of $\mathrm{pH}$ at $30{ }^{\circ} \mathrm{C}$. Samples were agitated at $175 \mathrm{rpm}$ for various periods of time. Then $30 \mathrm{~mL}$ of these solutions at some intervals of time were filtered and their concentrations were measured with ICP-AES. The sorption capacities were calculated from Eq. (6).

\subsection{Sorption isotherms}

Equilibrium batch sorption studies were carried out by placing $10 \mathrm{~g}$ of wet chitosan beads into $200 \mathrm{~mL}$ solutions containing $\mathrm{Cu}$ (II) and/or $\mathrm{Zn}$ (II) ions at various initial concentrations, with a sorbent dose of $50 \mathrm{~g} / \mathrm{L}$. The initial concentration of $\mathrm{Cu}(\mathrm{II})$ and $\mathrm{Zn}$ (II) ions in the one-component solutions ranged from $20 \mathrm{mg} / \mathrm{L}$ to $1200 \mathrm{mg} / \mathrm{L}$. The initial concentration of $\mathrm{Cu}$ (II) and $\mathrm{Zn}$ (II) ions in two-component solutions ranged from $20 \mathrm{mg} / \mathrm{L}$ to $800 \mathrm{mg} / \mathrm{L}$. The sorption equilibrium in two-component systems was studied in solutions containing $\mathrm{Cu}(\mathrm{II})$ and $\mathrm{Zn}$ (II) at different ratios of concentration 1:1, 1:2, 2:1. Then flasks were placed in an incubator shaker at $30{ }^{\circ} \mathrm{C}$ and were agitated at $175 \mathrm{rpm}$ for various periods of time. The concentration of $\mathrm{Cu}(\mathrm{II})$ and $\mathrm{Zn}(\mathrm{II})$ ions in the solution was analyzed with ICP-AES.

\section{RESULTS AND DISCUSSION}

\subsection{FTIR study of the chitosan gel beads}

Our studies of Fourier transform infrared spectroscopy (FTIR) of chitosan gel beads were performed to determine the molecular structure of intermolecular interactions between the components in chitosan 
gel beads. FTIR absorption spectra show the absorbance dependence on the wave number. The results of FTIR spectra are shown in Fig. 1.

The major peaks of the chitosan gel beads are located around $3620 \mathrm{~cm}^{-1}$ for $-\mathrm{OH}$ stretching vibration polysaccharide chain and $1651 \mathrm{~cm}^{-1}$ for $-\mathrm{NH}_{2}$ stretching vibration. Another peak at $2920-2860 \mathrm{~cm}^{-1}$ can be attributed to $-\mathrm{CH}$ stretching vibrations. The carbonyl bond $(\mathrm{C}=\mathrm{O})$ derived from chitin can be observed in the spectrum of $1651 \mathrm{~cm}^{-1}$. The polysaccharide stretching vibration $(\mathrm{C}=\mathrm{H})$ is located around $1100 \mathrm{~cm}^{-1}$. The hydrogen bonds between the polysaccharide chains are broken at the expense of interaction with metal cations. Thus chitosan material becomes more amorphous. The peak at $1020 \mathrm{~cm}^{-}$ ${ }^{1}$ can be attributed to stretching vibration of the bond C-O in polysaccharide chains (Wu et al., 2008).

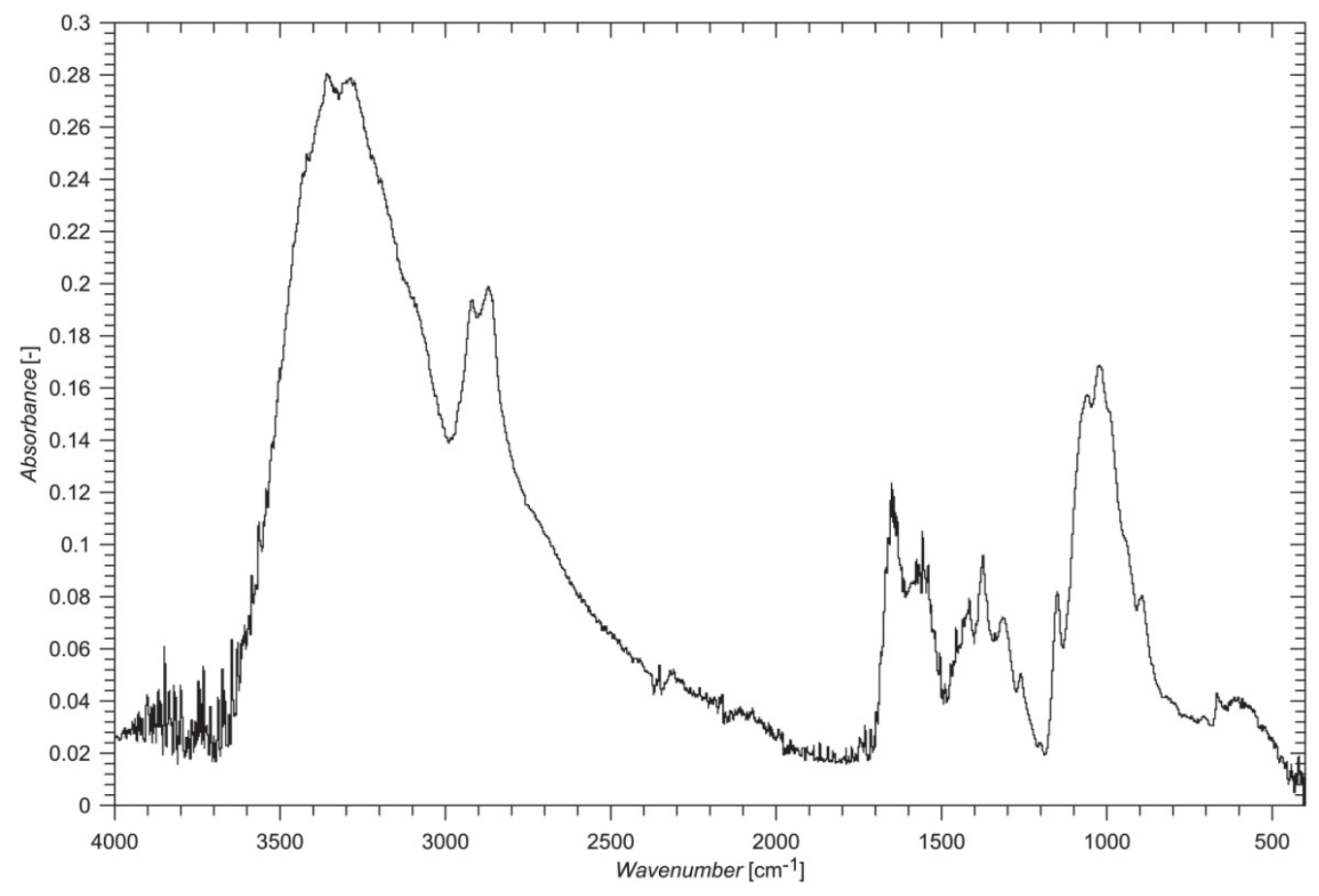

Fig. 1. FTIR spectrum of chitosan gel beads

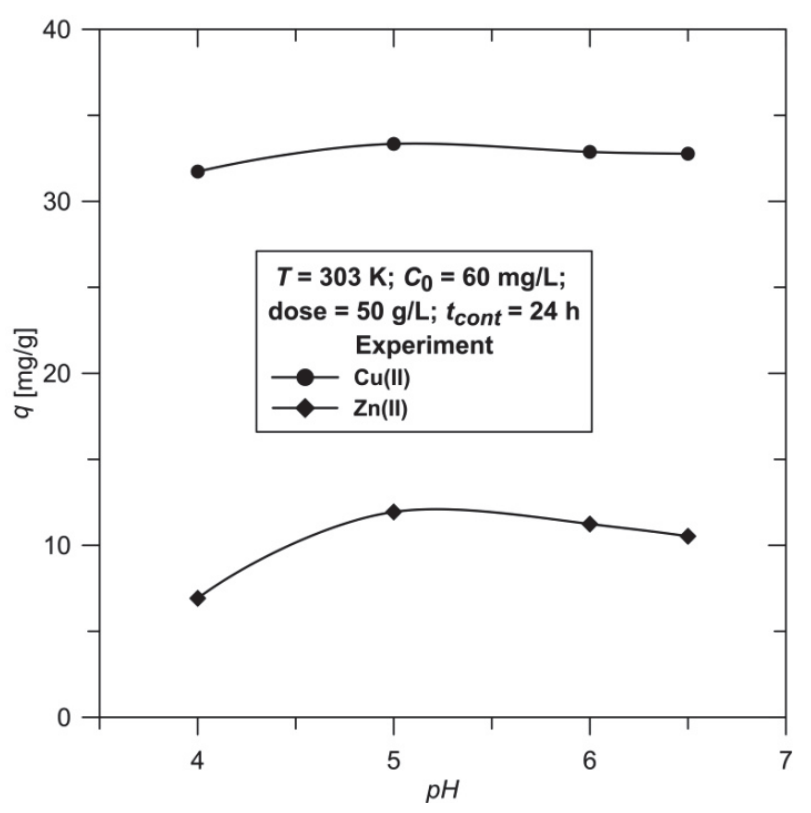

Fig. 2. $\mathrm{pH}$ effect on the sorption capacity of $\mathrm{Cu}(\mathrm{II})$ or $\mathrm{Zn}(\mathrm{II})$ ions on chitosan gel beads from one-component aqueous solutions

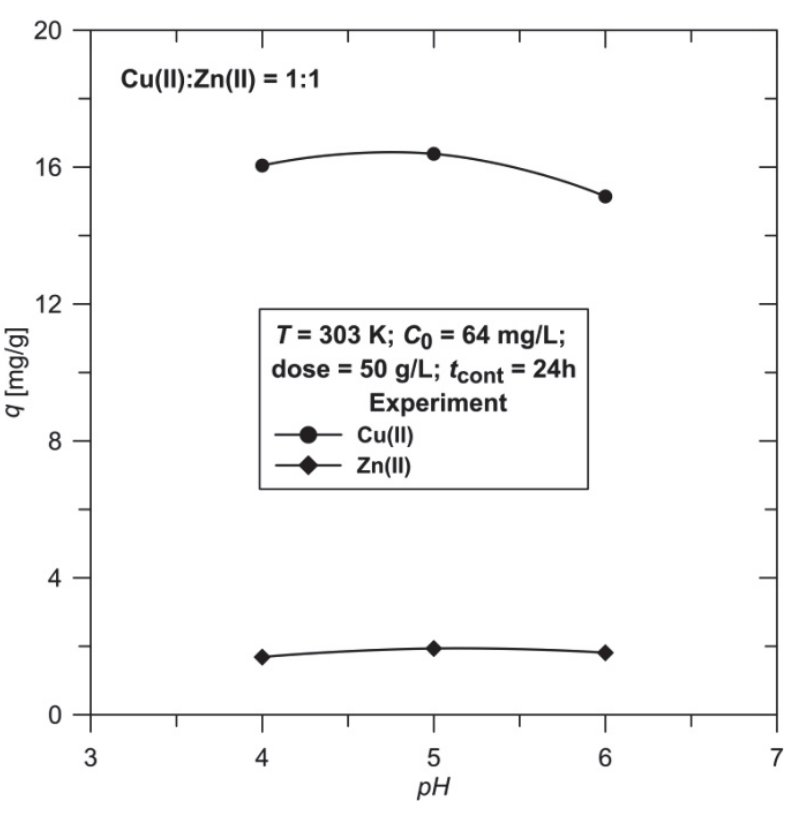

Fig. 3. pH effect on the sorption capacity of $\mathrm{Cu}(\mathrm{II})$ and $\mathrm{Zn}$ (II) ions on chitosan gel beads from two-component aqueous solution 


\subsection{Sorption effects}

\subsection{1. pH effects}

The $\mathrm{pH}$ of a solution affects the adsorption capacity of chitosan. The effect of the $\mathrm{pH}$ of a solution on the sorption of $\mathrm{Cu}$ (II) and $\mathrm{Zn}$ (II) ions on chitosan gel beads was investigated in the range of $\mathrm{pH}$ from 4.0 to 6.5 and from 4.0 to 6.0 for one- and two-component systems, respectively. Higher values of solution $\mathrm{pH}$ were not tested due to the fact that in $\mathrm{pH}$ higher than 7 precipitation of $\mathrm{Cu}(\mathrm{II})$ or $\mathrm{Zn}$ (II) may occur. Results are shown in Figs 2 and 3. It can be seen from these figures that there is a slight increase in sorption capacity with an increase in solution $\mathrm{pH}$. For both one- and two-component solutions it is evident that there are small differences in the sorption capacity for $\mathrm{pH}$ ranging between 5.0 and 6.0.

The maximum sorption capacity of $\mathrm{Cu}(\mathrm{II})$ and $\mathrm{Zn}$ (II) ions occurs at $\mathrm{pH} 5$ for both metal ions. This is because in acidic solutions, more protons will be available to protonate amine groups to form groups $\mathrm{NH}_{3}$, reducing the number of binding sites for the adsorption of $\mathrm{Cu}(\mathrm{II})$ and/or $\mathrm{Zn}(\mathrm{II})$. Whereas, at higher solution $\mathrm{pH}$ adsorption increases due to the decreased inhibitory effect of $\mathrm{H}^{+}$(Wan Ngah et al., 2005). Therefore heavy metal ions were better sorbed by chitosan at higher solution $\mathrm{pH}$.

The optimum $\mathrm{pH}$ values were determined for $\mathrm{Cu}(\mathrm{II})$ and $\mathrm{Zn}(\mathrm{II})$ as $\mathrm{pH} 5.0$ for one- and two- component solutions. The optimum $\mathrm{pH}$ values were used in further one-component experimental studies, such as the dose of chitosan gel beads or the contact time.

\subsubsection{Effect of sorbent dose}

The dependence of metal ion sorption on the dose of wet chitosan gel beads was studied using various amounts of sorbent in the range of 25-75 g/L. Results in Fig. 4 show that the sorption capacities of metal ions in sorbent sample slightly increase with the increase of the sorbent dose. The sorption capacity of $\mathrm{Cu}$ (II) was considerably greater than that of $\mathrm{Zn}(\mathrm{II})$ in the dose range of $25-75 \mathrm{~g} / \mathrm{L}$.

\subsubsection{Effect of contact time}

The effect of contact time on the sorption of $\mathrm{Cu}$ (II) and $\mathrm{Zn}$ (II) ions on chitosan gel beads was investigated and experimental results are presented in Figs 5 and 6. The effect of contact time is an important parameter because it reflects sorption kinetics. The concentration of metal ions in the sorbent increases rapidly at the initial sorption stage, and then remains constant. Sorption equilibrium was reached within about $1000 \mathrm{~min}$ for $\mathrm{Cu}(\mathrm{II})$ and $240 \mathrm{~min}$ for $\mathrm{Zn}(\mathrm{II})$.

The maximum value of metal ion concentration in relationship of $q_{t}$ versus time $\mathrm{t}$ (contact time) at a constant ion concentration $C_{0}$ is a separate point in sorption isotherm. Simultaneously, the relation of contact time is used in modeling of process kinetics (relationship of $q_{t}$ versus $t$ at the given $q_{e}$ ). In order to investigate the sorption mechanism, rate constants of sorption kinetics have to be determined. The pseudo-first order kinetic model can be presented in a linear form (Repo et al., 2010):

$$
\log \left(q_{e}-q_{t}\right)=\log q_{e}-\frac{k_{1}}{2.303} t
$$

The pseudo-second order kinetic model can be presented in another linear form (Repo et al., 2010):

$$
\frac{t}{q_{t}}=\frac{1}{k_{2} q_{e}{ }^{2}}+\frac{1}{q_{e}} t
$$

Constants of pseudo-first and pseudo-second order kinetic models were determined by least squares method using the linear regression. 


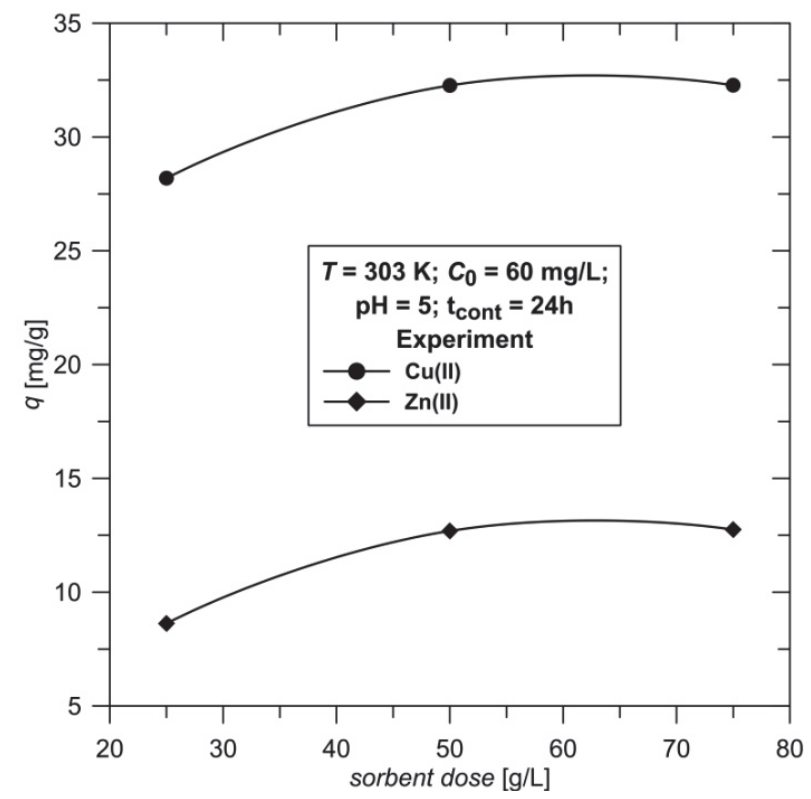

Fig. 4. Dose effect of chitosan gel beads on sorption capacity of $\mathrm{Cu}(\mathrm{II})$ ions and $\mathrm{Zn}$ (II) from one-component solutions

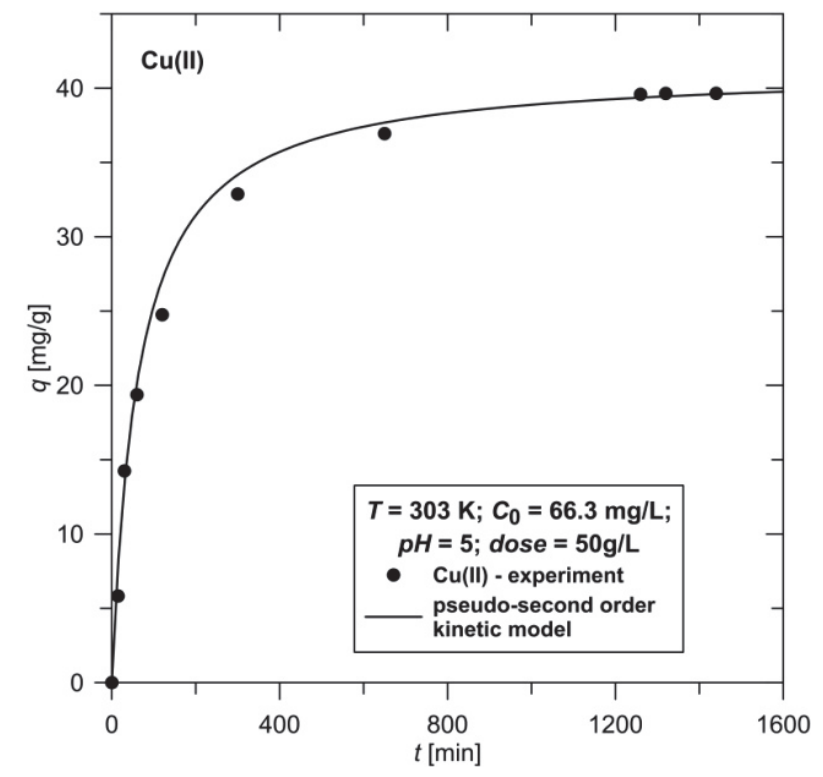

Fig. 5. Effect of contact time of chitosan gel beads in aqueous solution of $\mathrm{Cu}(\mathrm{II})$ ions on sorption capacity

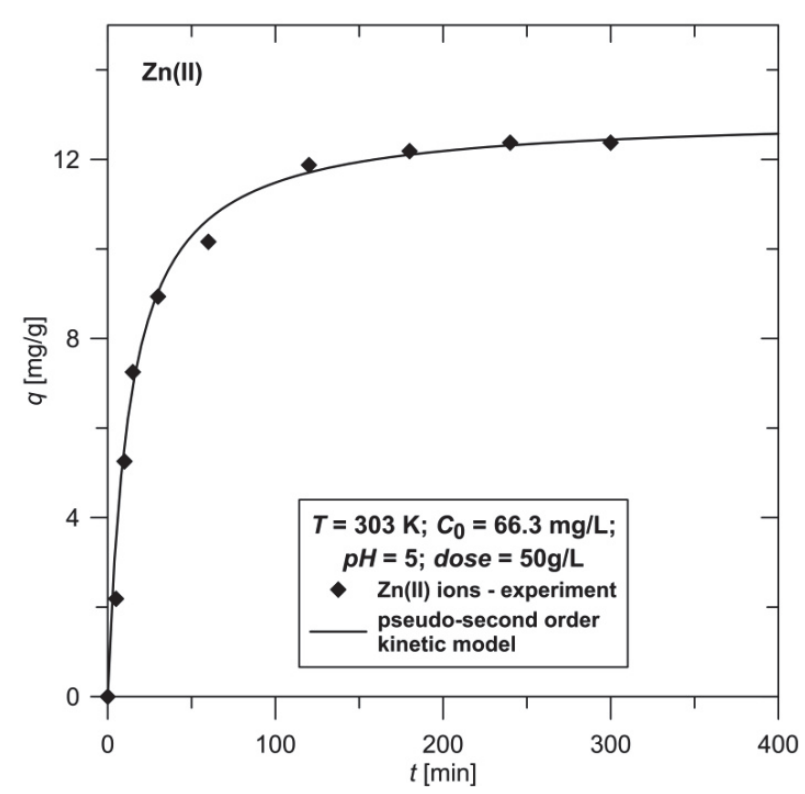

Fig. 6. Effect of contact time of chitosan gel beads in aqueous solution of $\mathrm{Zn}(\mathrm{II})$ ions on sorption capacity

The average relative errors $\delta[\%]$, which are the measure of fit accuracy of rate constants to experimental data, were calculated from the following equation:

$$
\delta=\frac{1}{N} \sum_{i=1}^{N}\left|\frac{q_{\exp _{i}}-q_{\text {calc }_{i}}}{q_{\exp _{i}}}\right|
$$

The obtained values of pseudo-first order $\left(k_{1}\right)$ and pseudo-second order $\left(k_{2}\right)$ rate constants, the average relative errors $(\delta)$ and determination coefficient $\left(R^{2}\right)$ are shown in Table 1. It is evident that the pseudofirst order kinetic model gave a very poor approximation of the experimental data.

The correlated results of the pseudo-second order kinetic model for $\mathrm{Cu}(\mathrm{II})$ and $\mathrm{Zn}$ (II) ions, according to Eq. (8), are presented in Figs. 5 and 6, respectively. 
Table 1. Approximated pseudo-first order and pseudo-second order kinetic rate constants for $\mathrm{Cu}$ (II) and $\mathrm{Zn}$ (II) ions on chitosan gel beads. $T=303 \mathrm{~K}, \mathrm{pH}=5$, dose $=50 \mathrm{~g} / \mathrm{L}$

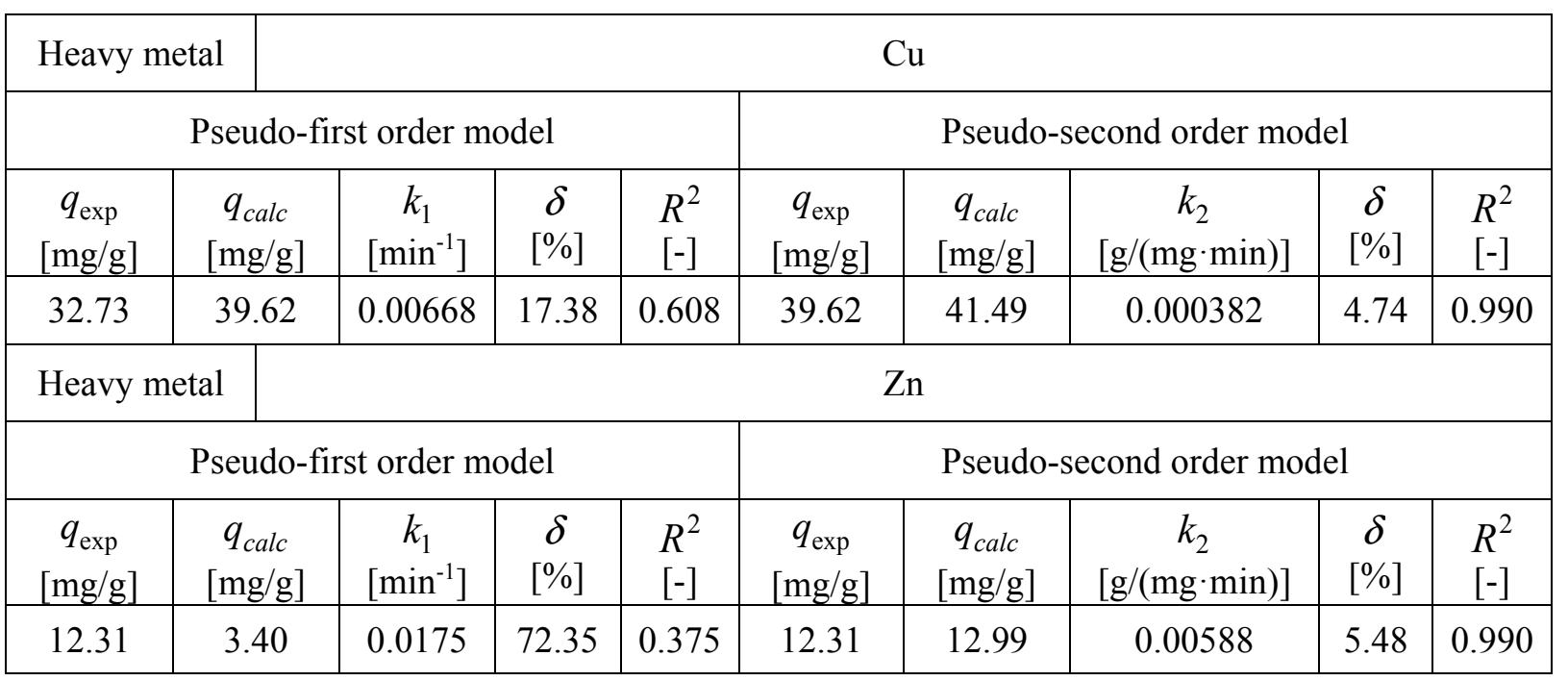

For the second-order kinetic model the average relative error $(\delta)$ was $4.74 \%$ for $\mathrm{Cu}(\mathrm{II})$ ions and $5.48 \%$ for $\mathrm{Zn}(\mathrm{II})$ ions. Therefore the pseudo-second order kinetic model is better for describing the sorption kinetics of the analyzed heavy metals. Our data were also consistent with other literature data (Corrigan and Koble, 1952; Ho and McKay, 1999; Kousalya et al., 2010; Repo et al., 2010; Runping et al., 2006). Furthermore, it is known that when the pseudo-second order kinetic model shows the best fitting to the experimental data, the sorption mechanism involves chemisorption (Wang et al., 2012).

\subsection{Sorption isotherm determination for one-component systems}

The analysis of sorption process equilibrium requires determination of the isotherm. Sorption isotherm is the most significant factor for analyzing the nature of adsorbate-adsorbent interaction. The sorption equilibrium studies of $\mathrm{Cu}(\mathrm{II})$ and $\mathrm{Zn}$ (II) ions on chitosan gel beads were described by six of the most common three-parameter equilibrium models: Langmuir-Freundlich, Redlich- Peterson, Sips and Koble-Corrigan, Hill and Toth.

Langmuir-Freundlich isotherm equation is a modification of the Langmuir and Freundlich equilibrium models providing a common isotherm equation called Langmuir-Freundlich (Chen, 2013; Wang et al., 2012; Hamdaoui and Naffrechoux, 2007; Kousalya et al., 2010; Onsosyen and Skaugrud 1990; Oyrton et al., 1999; Repo et al., 2010; Rinaudo, 2006; Wang et al., 2004):

$$
q_{e}=\frac{q_{m L F} K_{L F} C_{e}^{n_{L F}}}{1+K_{L F} C_{e}^{n_{L F}}}
$$

The three-parameter Redlich-Peterson equilibrium model is another combination of Freundlich and Langmuir equilibrium models and is intended to describe the heterogeneity of the sorbent surface. The Redlich-Peterson isotherm equation is given by (Repo et al., 2010):

$$
q_{e}=\frac{K_{R P} C_{e}}{1+B_{R P} C_{e}^{n_{R P}}}
$$

Koble-Corrigan equilibrium model is also a three-parameter empirical model which is also another combination of the Langmuir and Freundlich isotherm equations. Koble-Corrigan equilibrium model is given by (Han et al., 2005): 


$$
q_{e}=\frac{K_{K C} C_{e}^{n_{K C}}}{1+B_{K C} C_{e}^{n_{K C}}}
$$

Sips proposed one more equation similar in form to the Langmuir-Freundlich isotherm equation (Chen, 2013; Repo et al, 2010):

$$
q_{e}=\frac{q_{m S}\left(K_{S} C_{e}\right)^{n_{S}}}{1+\left(K_{S} C_{e}\right)^{n_{S}}}
$$

Hill isotherm equation describes the binding of different species on homogeneous sorbent surface. This model assumes that sorption is a phenomenon concerned with the binding abilities of ligands at one site on the macromolecule. It may influence different binding sites of the same macromolecule (Chen, 2013):

$$
q_{e}=\frac{q_{m H} C_{e}^{n_{H}}}{K_{H}+C_{e}^{n_{H}}}
$$

Toth proposed an equilibrium model which is expressed in the following form (Lodeiro et al., 2005):

$$
q_{e}=\frac{q_{m T} K_{T} C_{e}}{\left(1+\left(K_{T} C_{e}\right)^{n_{T}}\right)^{1 / n_{T}}}
$$

Table 2. Approximated parameters and average relative errors of various equilibrium models for $\mathrm{Cu}(\mathrm{II})$ and $\mathrm{Zn}$ (II) ions on the chitosan gel beads

\begin{tabular}{|c|c|c|c|c|c|c|c|c|c|c|}
\hline \multicolumn{7}{|c|}{ Langmuir-Freundlich isotherm constants } & \multicolumn{5}{c|}{ Redlich-Peterson isotherm constants } \\
\hline & $q_{m L F}[\mathrm{mg} / \mathrm{g}]$ & $K_{L F}[\mathrm{~L} / \mathrm{mg}]$ & $n_{L F}[-]$ & $\delta[\%]$ & & $K_{R P}[\mathrm{~L} / \mathrm{g}]$ & $B_{R P}[\mathrm{~L} / \mathrm{mg}]$ & $n_{R P}[-]$ & $\delta[\%]$ \\
\hline $\mathrm{Cu}^{2+}$ & 283.63 & 0.1027 & 0.454 & 3.06 & $\mathrm{Cu}^{2+}$ & 50.94 & 1.0387 & 0.792 & 8.38 \\
\hline $\mathrm{Zn}^{2+}$ & 145.11 & 0.0001 & 1.973 & 5.61 & $\mathrm{Zn}^{2+}$ & 0.705 & 0.0006 & 1.276 & 50.03 \\
\hline \multicolumn{7}{|c|}{ Koble-Corrigan isotherm constants } & \multicolumn{7}{|c|}{ Sips isotherm constants } \\
\hline & $K_{K C}[\mathrm{~L} / \mathrm{g}]$ & $B_{K C}[\mathrm{~L} / \mathrm{mg}]$ & $n_{K C}[-]$ & $\delta[\%]$ & & $q_{m S}[\mathrm{mg} / \mathrm{g}]$ & $K_{S}[\mathrm{~L} / \mathrm{mg}]$ & $n_{S}[-]$ & $\delta[\%]$ \\
\hline $\mathrm{Cu}^{2+}$ & 29.12 & 0.1027 & 0.454 & 3.06 & $\mathrm{Cu}^{2+}$ & 283.57 & 0.0067 & 0.455 & 3.06 \\
\hline $\mathrm{Zn}^{2+}$ & 0.012 & 0.0001 & 1.973 & 12.36 & $\mathrm{Zn}^{2+}$ & 144.29 & 0.0084 & 2.030 & 6.36 \\
\hline \multicolumn{7}{|c|}{$\mathrm{Hill}$ isotherm constants } & & Toth isotherm constants & \\
\hline & $q_{m H}[\mathrm{mg} / \mathrm{g}]$ & $K_{H}[\mathrm{mg} / \mathrm{L}]$ & $n_{H}[-]$ & $\delta[\%]$ & $q_{m T}[\mathrm{mg} / \mathrm{g}]$ & $K_{T}[\mathrm{~L} / \mathrm{mg}]$ & $n_{T}[-]$ & $\delta[\%]$ \\
\hline $\mathrm{Cu}^{2+}$ & 283.64 & 9.741 & 0.454 & 3.05 & $\mathrm{Cu}^{2+}$ & 61.34 & 1.049 & 0.792 & 34.83 \\
\hline $\mathrm{Zn}^{2+}$ & 144.29 & 16390.2 & 2.029 & 6.36 & $\mathrm{Zn}^{2+}$ & 178.91 & 0.00216 & 1.577 & 25.03 \\
\hline
\end{tabular}

The constants of the Langmuir-Freundlich (Eq. (10)), Redlich-Peterson (Eq. (11)) Koble-Corrigan (Eq. (12)), Sips (Eq. (13)), Hill (Eq. (14)) and Toth (Eq. (15)) equilibrium models were fitted to the experimental data of $\mathrm{Cu}(\mathrm{II})$ and $\mathrm{Zn}(\mathrm{II})$ ions and results are shown in Table 2. These fitted constants were determined using the quasi-Newton nonlinear estimation method with Statistica software.

The equilibrium models fitted to the one-component sorption experimental data of $\mathrm{Cu}$ (II) and $\mathrm{Zn}$ (II) ions on chitosan gel beads are shown in Figs. 7 and 8. The obtained maximum sorption capacities $\left(q_{m}\right)$ equaled $191.25 \mathrm{mg} / \mathrm{g}$ for $\mathrm{Cu}$ (II) ions (Fig. 7) and $142.88 \mathrm{mg} / \mathrm{g}$ for Zn(II) ions (Fig. 8). 


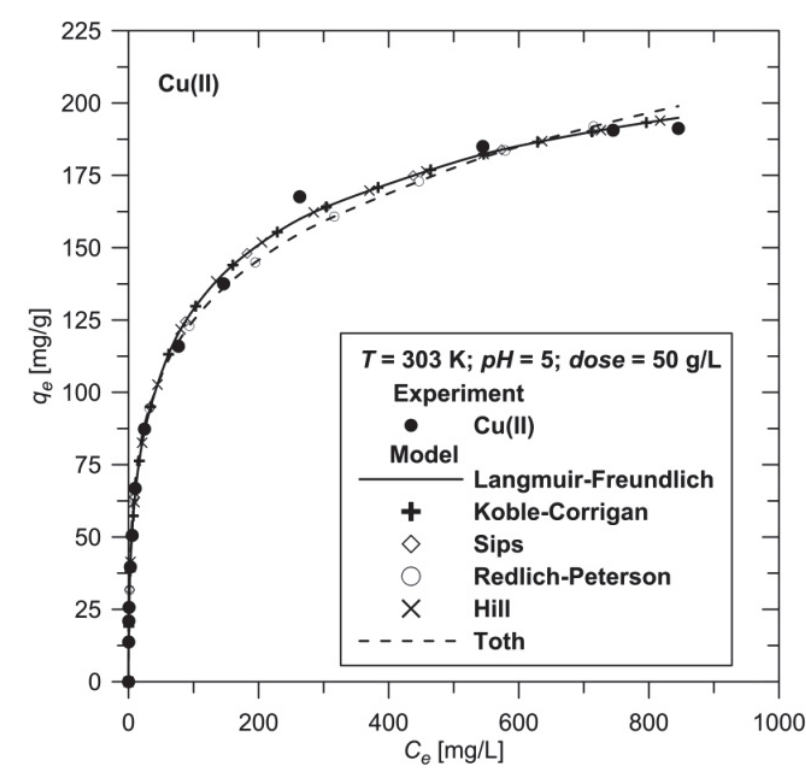

Fig. 7. Experimental and fitted sorption isotherms of $\mathrm{Cu}$ (II) ions on chitosan gel beads using various equilibrium models

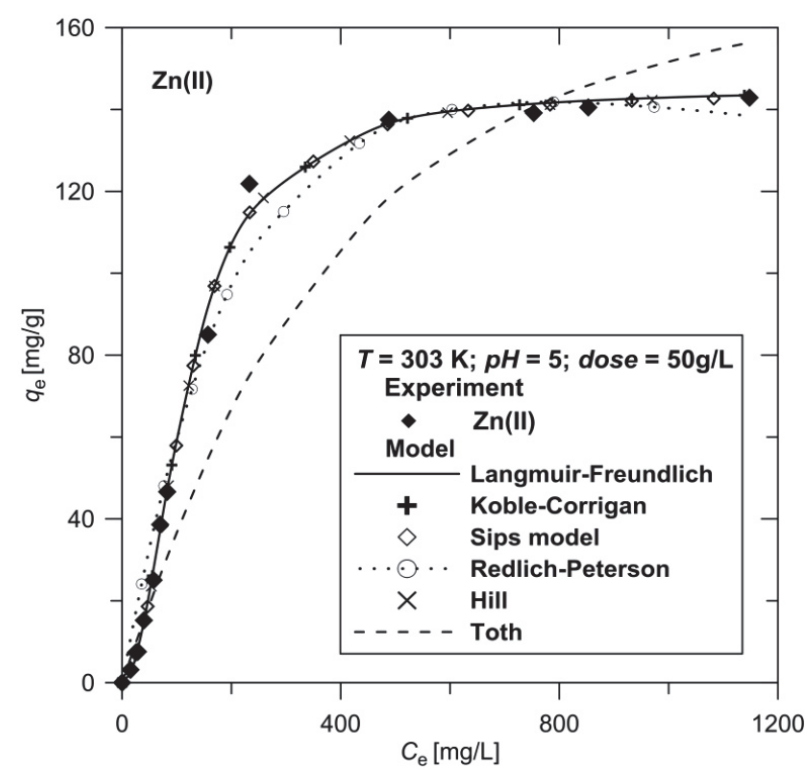

Fig. 8. Experimental and fitted sorption isotherms of $\mathrm{Zn}(\mathrm{II})$ ions on chitosan gel beads using various equilibrium models

From analysis of Table 2 it can be concluded that the Langmuir-Freundlich, Hill and Sips equilibrium models approximate well the sorption behavior. These isotherm functions overlap in Figs. 7 and 8 . Their average relative error $(\delta)$ for $\mathrm{Cu}(\mathrm{II})$ is about $3 \%$. For $\mathrm{Zn}(\mathrm{II})$ the errors are similar and vary in the range from $5.61 \%$ to $6.36 \%$. Also Koble-Corrigan equilibrium model quite well describes the experimental data. Its average relative error for $\mathrm{Cu}(\mathrm{II})$ has the same low value as the best models ( $\delta=3.06 \%$ ). However, the error for $\mathrm{Zn}(\mathrm{II})$ ions is greater $(\delta=12.36 \%)$. Redlich-Peterson and Toth model gave the worst fitting results with high errors, especially for $\mathrm{Zn}(\mathrm{II})$ ions.

Based on the average relative errors $(\delta)$ for both metal ions, the equilibrium models fit accuracy to the experimental data of $\mathrm{Cu}(\mathrm{II})$ and $\mathrm{Zn}(\mathrm{II})$ ions is in the following order: LangmuirFreundlich $>$ Hill $>$ Sips $>$ Koble-Corrigan $>$ Redlich-Peterson $>$ Toth.

\subsection{Sorption isotherm determination for two-component systems}

In the last decade there were several examples of empirical isotherm models, which provide parameters derived from a one-component system. Unfortunately, some models fail when interactions between metals in the mixture occur. The maximum sorption capacity $\left(q_{m}\right)$ and heterogeneity factor $(n)$ depend on the concentrations of other components in the mixture. Therefore, the most desirable approach to two-component system modeling is an estimation of two-component isotherm on the basis of the association constant derived from one-component isotherms: $K_{L F}, K_{R P}, K_{K C}, K_{S}, K_{H}, K_{T}$ for LangmuirFreundlich, Redlich-Peterson, Koble-Corrigan, Sips, Hill and Toth, respectively. In our study, the equilibrium data of two-component systems was modeled using the extended forms of the threeparameter isotherm equations such as: Langmuir-Freundlich, Koble-Corrigan, Sips, Redlich-Peterson, Hill and Toth. They are presented in Table 3.

These modeling calculations were carried out using Maple software (Maplesoft) by means of nonlinear programming based on the modified Newton method. Unknown parameters were estimated by minimizing the objective function $e(\mathrm{Q} i, 2003)$ for combined data of all concentration ratios:

$$
e=\sum_{i} \sum_{j}\left(q_{\exp _{i j}}-q_{c a l c_{i j}}\right)^{2}
$$

where $i$ and $j$ are the first and second component in the particular two-component mixture. 
Table 3. Extended forms of the three-parameter isotherm equations for two metal ions

\begin{tabular}{|c|c|c|}
\hline $\begin{array}{l}\text { Two-component } \\
\text { isotherm }\end{array}$ & Equation system & Literature \\
\hline $\begin{array}{l}\text { Langmuir- } \\
\text { Freundlich }\end{array}$ & $\begin{array}{l}q_{e 1}=\frac{q_{m 1 L F} K_{1 L F} C_{1 e}^{n_{1} L F}}{1+K_{1 L F} C_{1 e}^{n_{1 L F}}+K_{2 L F} C_{2 e}^{n_{2} L F}} \\
q_{e 2}=\frac{q_{m 2 L F} K_{2 L F} C_{2 e}^{n_{2} L F}}{1+K_{1 L F} C_{1 e}^{n_{1 L F}}+K_{2 L F} C_{2 e}^{n_{2} L F}}\end{array}$ & (Vieira et al., 2007) \\
\hline Redlich-Peterson & $\begin{array}{l}q_{e 1}=\frac{K_{1 R P} C_{1 e}}{1+B_{1 R P} C_{1 e}^{n_{1 R P}}+B_{2 R P} C_{2 e}^{n_{2 R P}}} \\
q_{e 2}=\frac{K_{2 R P} C_{2 e}}{1+B_{1 R P} C_{1 e}^{n_{1 R P}}+B_{2 R P} C_{2 e}^{n_{2 R P}}}\end{array}$ & $\begin{array}{c}\text { (Sulaymon et al., } \\
\text { 2011) }\end{array}$ \\
\hline Koble-Corrigan & $\begin{array}{l}q_{e 1}=\frac{K_{1 K C} C_{1 e}^{n_{1} K C}}{1+B_{1 K C} C_{1 e}^{n_{1} K C}+B_{2 K C} C_{2 e}^{n_{2} K C}} \\
q_{e 2}=\frac{K_{2 K C} C_{2 e}^{n_{2} K C}}{1+B_{1 K C} C_{1 e}^{n_{1 K C}}+B_{2 K C} C_{2 e}^{n_{2} K C}}\end{array}$ & (Nastaj, 2013) \\
\hline Sips & $\begin{array}{l}q_{e 1}=\frac{q_{m 1 S}\left(K_{1 S} C_{1 e}\right)^{n_{1 S}}}{1+\left(K_{1 S} C_{1 e}\right)^{n_{1 S}}+\left(K_{2 S} C_{2 e}\right)^{n_{2 S}}} \\
q_{e 2}=\frac{q_{m 2 S}\left(K_{2 S} C_{2 e}\right)^{n_{2 S}}}{1+\left(K_{1 S} C_{1 e}\right)^{n_{1 S}}+\left(K_{2 S} C_{2 e}\right)^{n_{2 S}}}\end{array}$ & $\begin{array}{c}\text { (Al-Asheh et al., } \\
\text { 2000; Repo et al., } \\
\text { 2010) }\end{array}$ \\
\hline Hill & $\begin{array}{l}q_{e 1}=\frac{q_{m 1 H} C_{1 e}^{n_{1} H}}{K_{1 H}+C_{1 e}^{n_{1} H}+K_{2 H}+C_{2 e}^{n_{2 H}}} \\
q_{e 2}=\frac{q_{m 2 H} C_{2 e}^{n_{2 H}}}{K_{1 H}+C_{1 e}^{n_{1} H}+K_{2 H}+C_{2 e}^{n_{2 H}}}\end{array}$ & $\begin{array}{c}\text { (Al-Asheh et al., } \\
\text { 2003) }\end{array}$ \\
\hline Toth & $\begin{array}{l}q_{e 1}=\frac{q_{m 1 T} K_{1 T} C_{1 e}^{n_{1 T}}}{\left(1+\left(K_{1 T} C_{1 e}\right)^{n_{1} T}\right)^{1 / n_{1} T}+\left(1+\left(K_{2 T} C_{2 e}\right)^{n_{2} T}\right)^{1 / n_{2} T}} \\
q_{e 2}=\frac{q_{m 2 T} K_{2 T} C_{2 e}^{n_{2 T}}}{\left(1+\left(K_{1 T} C_{1 e}\right)^{n_{1} T}\right)^{1 / n_{1} T}+\left(1+\left(K_{2 T} C_{2 e}\right)^{n_{2} T}\right)^{1 / n_{2} T}}\end{array}$ & (Allen et al., 2004) \\
\hline
\end{tabular}

Two-component sorption studies were conducted in three initial concentration ratios ( $\mathrm{Cu}(\mathrm{II})-\mathrm{Zn}(\mathrm{II})$ 1:1, $1: 2,2: 1)$ at a constant $\mathrm{pH}$, constant sorbent dose and constant temperature. The initial concentrations were in the range of $22.224-1135.392 \mathrm{mg} / \mathrm{L}$ for $\mathrm{Cu}(\mathrm{II})$ ions and $20.416-1377.312 \mathrm{mg} / \mathrm{L}$ for $\mathrm{Zn}$ (II) ions. Results are presented in Table 4 and Figs. 9 through 11.

Very high values of the average relative errors $\delta \%$ were obtained for extended models of RedlichPeterson and Toth. Thus, results of these two-component models are unsuitable for description of $\mathrm{Cu}$ (II) and $\mathrm{Zn}$ (II) ion sorption and therefore are not presented here. Hill model was also omitted due to similarity of obtained results to those for Sips isotherm.

For the one-component systems it was evident that sorption capacity of $\mathrm{Cu}(\mathrm{II})$ was insignificantly higher than that for $\mathrm{Zn}(\mathrm{II})$ ions (Figs 7 and 8). For two-component sorption studies, the maximum sorption capacity of $\mathrm{Cu}$ (II) ions was seven to twelve times higher than that of $\mathrm{Zn}$ (II) ions, for all the studied systems (Figs. 9 through 11). 


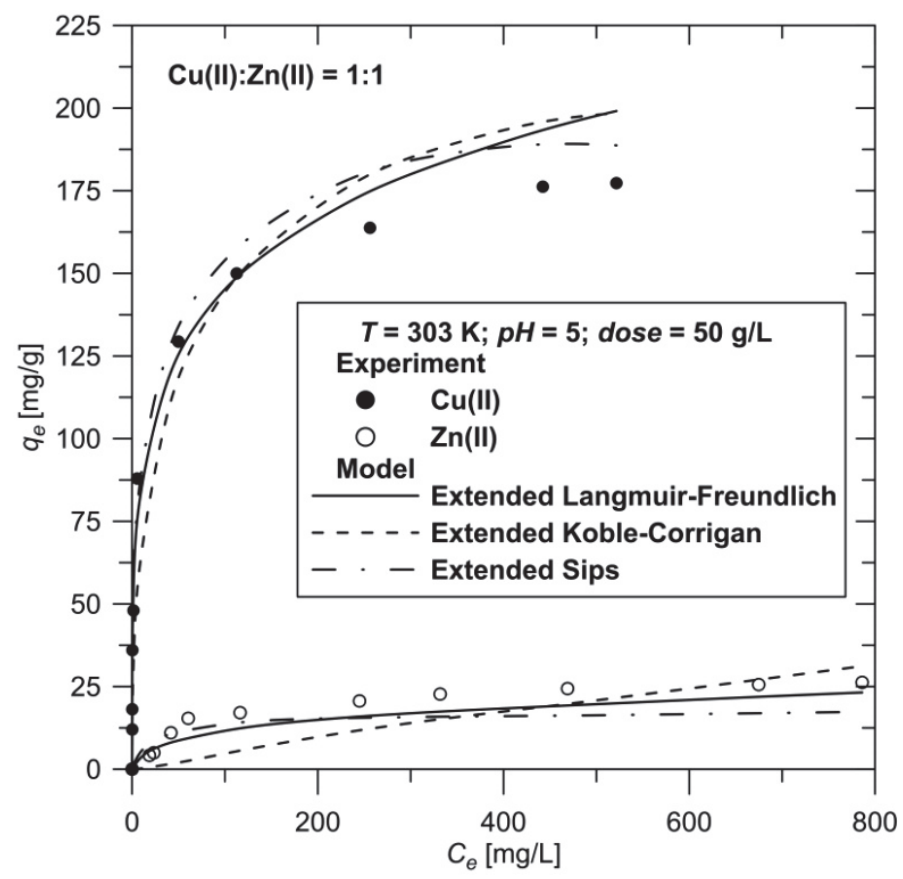

Fig. 9. Relationship of adsorption capacities of $\mathrm{Cu}(\mathrm{II})$ and $\mathrm{Zn}(\mathrm{II})$ on chitosan gel beads versus metal ion concentration in two-component equilibrium-initial concentration ratio 1:1. Experimental and various isotherm modeling data

Table 4. Approximated parameters and average relative errors of various extended equilibrium models for sorption of $\mathrm{Cu}(\mathrm{II})$ and $\mathrm{Zn}(\mathrm{II})$ ion mixture on chitosan gel beads

\begin{tabular}{|c|c|c|c|c|c|}
\hline \multicolumn{7}{|c|}{ Extended Langmuir-Freundlich model } \\
\hline$q_{m 1 L F}[\mathrm{mg} / \mathrm{g}]$ & $K_{1 L F}[\mathrm{~L} / \mathrm{mg}]$ & $n_{1 L F}[-]$ & $q_{m 2 L F}[\mathrm{mg} / \mathrm{g}]$ & $K_{2 L F}[\mathrm{~L} / \mathrm{mg}]$ & $n_{2 L F}[-]$ \\
\hline 528.98 & 0.103 & 0.284 & 16957.99 & 0.000080 & 0.497 \\
\hline$\delta_{1,1: 1}(\%)$ & $\delta_{1,2: 1}(\%)$ & $\delta_{1.1: 2}(\%)$ & $\delta_{2,1: 1}(\%)$ & $\delta_{2,2: 1}(\%)$ & $\delta_{2,1: 2}(\%)$ \\
\hline 20.13 & 18.33 & 15.65 & 22.09 & 12.56 & 75.75 \\
\hline \multicolumn{7}{|c|}{ Extended Koble-Corrigan model } \\
\hline$B_{1 K C}[\mathrm{~L} / \mathrm{mg}]$ & $K_{1 K C}[\mathrm{~L} / \mathrm{g}]$ & $n_{1 K C}[-]$ & $B_{2 K C}[\mathrm{~L} / \mathrm{mg}]$ & $K_{2 K C}[\mathrm{~L} / \mathrm{g}]$ & $n_{2 K C}[-]$ \\
\hline 0.074 & 29.12 & 0.469 & 0.00005 & 0.012 & 1.337 \\
\hline$\delta_{1,1: 1}(\%)$ & $\delta_{1,2: 1}(\%)$ & $\delta_{1,1: 2}(\%)$ & $\delta_{2,1: 1}(\%)$ & $\delta_{2,2: 1}(\%)$ & $\delta_{2,1: 2}(\%)$ \\
\hline 22.12 & 12.21 & 29.46 & 47.89 & 37.64 & 34.54 \\
\hline \multicolumn{7}{|c|}{ Extended Sips model } & \\
\hline$q_{m 1 S}[\mathrm{mg} / \mathrm{g}]$ & $K_{1 S}[\mathrm{~L} / \mathrm{mg}]$ & $n_{1 S}[-]$ & $q_{m 2 S}[\mathrm{mg} / \mathrm{g}]$ & $K_{2 S}[\mathrm{~L} / \mathrm{mg}]$ & $n_{2 S}[-]$ \\
\hline 656.0292 & 0.00667 & 0.394 & 32.38 & 0.00838 & 0.591 \\
\hline$\delta_{1,1: 1}(\%)$ & $\delta_{1,2: 1}(\%)$ & $\delta_{1,1: 2}(\%)$ & $\delta_{2,1: 1}(\%)$ & $\delta_{2,2: 1}(\%)$ & $\delta_{2,1: 2}(\%)$ \\
\hline 19.10 & 21.82 & 14.65 & 32.59 & 11.70 & 107.39 \\
\hline
\end{tabular}




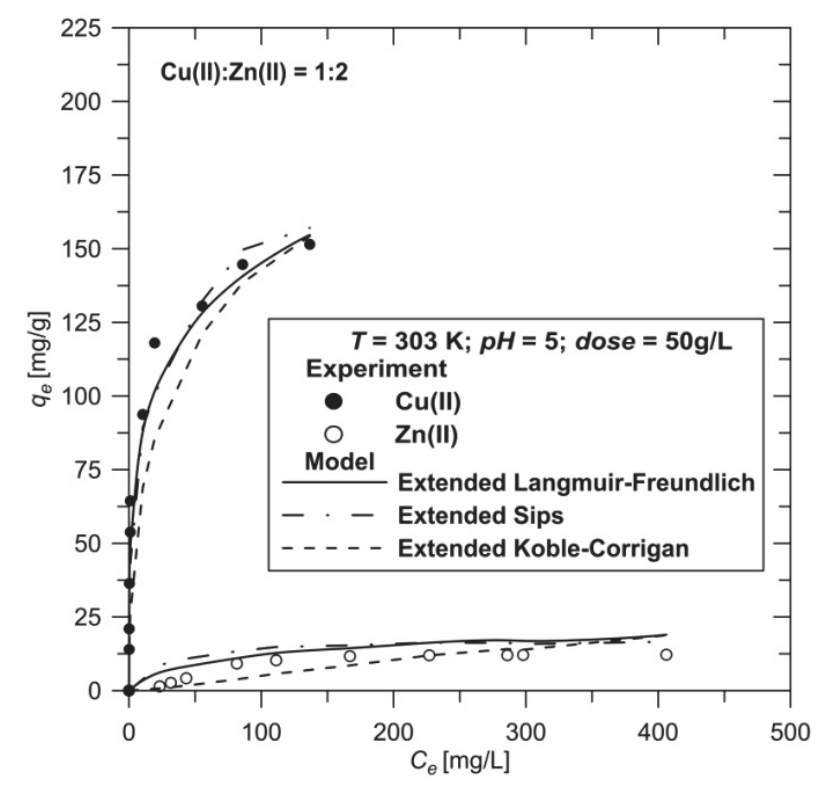

Fig. 10. Relationship of adsorption capacities of $\mathrm{Cu}$ (II) and $\mathrm{Zn}(\mathrm{II})$ on chitosan gel beads versus metal ion concentration in two-component equilibrium-initial concentration ratio 1:2. Experimental and various isotherm modeling data

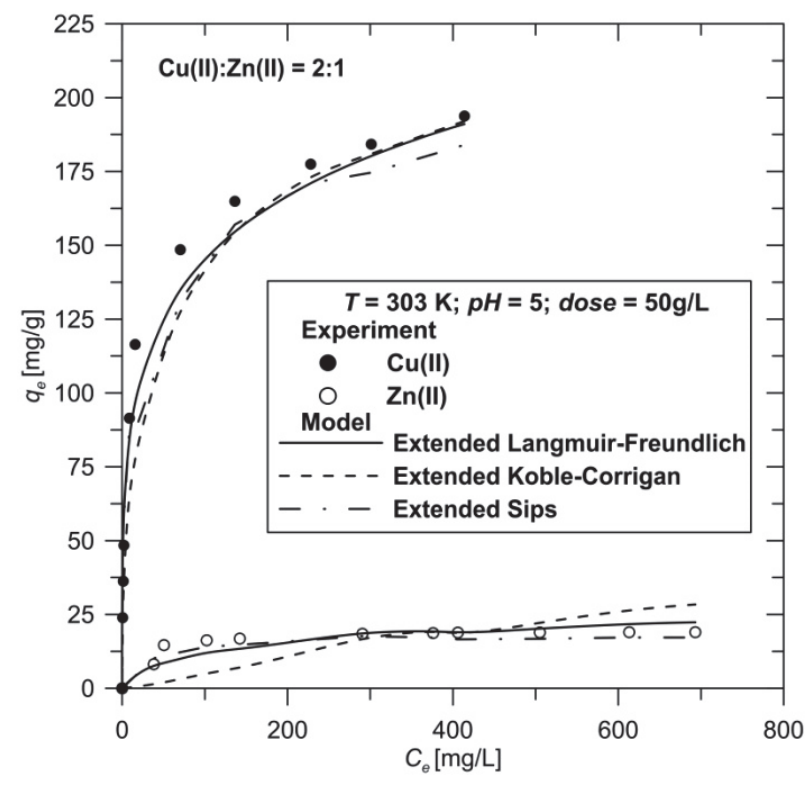

Fig. 11. Relationship of adsorption capacities of $\mathrm{Cu}$ (II) and $\mathrm{Zn}(\mathrm{II})$ on chitosan gel beads versus metal ion concentration in two-component equilibrium-initial concentration ratio 2:1. Experimental and various isotherm modeling data

From analysis of Figs. 9 through 11 one can conclude that the extended Langmuir-Freundlich model describes generally fairly well the sorption behavior in the two-component systems, except $\mathrm{Zn}$ (II) in the presence of $\mathrm{Cu}(\mathrm{II})$ for the concentration ratio of 1:2 $\left(\delta_{2}=75.75 \%\right)$. In other systems and concentration ratios, the error values vary from $12.56 \%$ to $22.09 \%$.

The extended Sips model gave the best fitting to the experimental data for the concentration ratio of $1: 1$ (Fig. 9) for $\mathrm{Cu}(\mathrm{II})$ in the presence of $\mathrm{Zn}(\mathrm{II})$. The average relative error $\left(\delta_{1}\right)$ equals $19.10 \%$, However, for $\mathrm{Zn}(\mathrm{II})$ ions in the presence of $\mathrm{Cu}(\mathrm{II})$ ions the average relative error $\left(\delta_{2}\right)$ is higher and equals $32.59 \%$. Taking into account both concentration ratios, relative errors for the extended Langmuir-Freundlich model $\left(\delta_{1}=20.13 \%, \delta_{2}=22.09 \%\right)$ are more uniformly distributed.

For the concentration ratio of 1:2, the most uniformly distributed average relative errors are obtained for Koble-Corrigan model $\left(\delta_{1}=29.46 \%, \delta_{2}=34.54 \%\right)$. Langmuir-Freundlich and Sips models gave lower values of the average relative errors only for $\mathrm{Cu}$ (II) in the presence of $\mathrm{Zn}$ (II) ions $\left(\delta_{1}=15.65 \%\right.$ and $\delta_{1}=14.65 \%$, respectively) and definitely higher values for $\mathrm{Zn}(\mathrm{II})$ ions in the presence of $\mathrm{Cu}$ (II) ions $\left(\delta_{2}=75.75 \%, \delta_{2}=107.39 \%\right.$, respectively).

Whereas, for the concentration ratio of 2:1 (Figure 11), for $\mathrm{Cu}(\mathrm{II})$ in the presence of $\mathrm{Zn}(\mathrm{II})$, the best fitting is provided by the extended Langmuir-Freundlich model. The average relative error $\left(\delta_{1}\right)$ for $\mathrm{Cu}$ (II) ions in the presence of $\mathrm{Zn}$ (II) ions equals $18.33 \%$ and for $\mathrm{Zn}$ (II) ions in the presence of $\mathrm{Cu}$ (II) ions $\left(\delta_{2}\right)$ equals $12.56 \%$. A slightly worse, but fairly good approximation is exhibited by the Sips model $\left(\delta_{1}=21.82 \%, \delta_{2}=11.70 \%\right)$.

\section{CONCLUSIONS}

In the study, sorptive removal of $\mathrm{Cu}$ (II) and $\mathrm{Zn}$ (II) ions from one- and two-component solutions on chitosan gel beads was investigated at $303 \mathrm{~K}$. The sorption of metal ions was not strongly depended on the $\mathrm{pH}$ of a solution and the dose of sorbent. Maximum heavy metal removal capacities from water solutions were obtained at $p H=5.0$ for $\mathrm{Cu}(\mathrm{II})$ and $\mathrm{Zn}$ (II) ions both in the one- and two-component 
systems. The optimum dose of sorbent was determined as $50 \mathrm{~g} / \mathrm{L}$ for all studied heavy metals. Equilibrium contact times were reached: for $\mathrm{Cu}$ (II) within about $1000 \mathrm{~min}$, whereas for $\mathrm{Zn}$ (II) ions within $240 \mathrm{~min}$. It was proved that the pseudo-second order kinetic model is adequate to describe the sorption kinetics of the mentioned heavy metals onto chitosan gel beads, which is consistent with other reports.

An attempt was made to explain sorption mechanism of the investigated heavy metals on chitosan gel beads. Amino groups of chitosan chain in which nitrogen is donor of the electron pairs are mainly responsible for the formation of complexes with heavy metal cations (Jin and Bai, 2002). Additionally, this mechanism depends on other factors such as: the $\mathrm{pH}$ of a solution, deacylation process and chitosan form.

The maximum sorption capacities $\left(q_{m}\right)$ in one-component solutions equaled $191.25 \mathrm{mg} / \mathrm{g}$ for $\mathrm{Cu}$ (II) ions and $142.88 \mathrm{mg} / \mathrm{g}$ for $\mathrm{Zn}(\mathrm{II})$ ions.

Six, most common three-parameter equilibrium models: Langmuir- Freundlich, Redlich-Peterson, Sips, Koble-Corrigan, Hill and Toth, were fitted to one-component experimental equilibrium sorption data. The accuracy of equilibrium model fittings for $\mathrm{Cu}(\mathrm{II})$ and $\mathrm{Zn}(\mathrm{II})$ ions were in the following order: Langmuir-Freundlich $>$ Hill $>$ Sips $>$ Koble-Corrigan $>$ Redlich-Peterson $>$ Toth. Finally, two-component equilibrium data were described by the extended Langmuir-Freundlich, Koble-Corrigan and Sips models, which were based on the previous modeling results obtained for the one-component systems. The overall best fitting accuracy was obtained for the Langmuir-Freundlich model.

As a result of the study, one can draw a conclusion that chitosan gel beads can be successfully used for removal of heavy metals both from one-component and two-component solutions. It can be attributed to strong affinity of chitosan gel beads to heavy metals. Additionally, chitosan gel beads are relatively easily manufactured and are therefore abundant sorbents. For this reason they can be recommended for use in the removal of heavy metals from wastewater.

This study was funded by development and research project for young scientist 517-10-013-3579/17.

\section{SYMBOLS}

$\begin{array}{ll}B_{K C} & \text { one-component Koble-Corrigan constant, } \mathrm{L} / \mathrm{mg} \\ B_{R P} & \text { one-component Redlich-Peterson constant, } \mathrm{L} / \mathrm{mg} \\ B_{l K C} & \text { Koble-Corrigan constant for } \mathrm{Cu}(\mathrm{II}) \text { in two-component mixture, } \mathrm{L} / \mathrm{mg} \\ B_{1 R P} & \text { Redlich-Peterson constant for } \mathrm{Cu}(\mathrm{II}) \text { in two-component mixture, } \mathrm{L} / \mathrm{mg} \\ B_{2 K C} & \text { Koble-Corrigan constant for } \mathrm{Zn}(\mathrm{II}) \text { in two-component mixture, } \mathrm{L} / \mathrm{mg} \\ B_{2 R P} & \text { Redlich-Peterson constant for } \mathrm{Zn}(\mathrm{II}) \text { in two-component mixture, } \mathrm{L} / \mathrm{mg} \\ C_{e} & \text { equilibrium liquid phase concentration of metal ion, } \mathrm{mg} / \mathrm{L} \\ C_{0} & \text { initial concentration of metal ion, } \mathrm{mg} / \mathrm{L} \\ C_{l e} & \text { equilibrium liquid phase concentration of } \mathrm{Cu}(\mathrm{II}) \text { ion in two-component mixture, } \mathrm{mg} / \mathrm{L} \\ C_{2 e} & \text { equilibrium liquid phase concentration of } \mathrm{Zn}(\mathrm{II}) \text { ion in two-component mixture, } \mathrm{mg} / \mathrm{L} \\ k_{1} & \text { rate constant of pseudo-first order kinetic model, min }{ }^{-1} \\ k_{2} & \text { rate constant of pseudo-second order kinetic model, g/(mg min) } \\ K_{H} & \text { one-component Hill isotherm constant, } \mathrm{mg} / \mathrm{L} \\ K_{K C} & \text { one-component Koble-Corrigan isotherm constant, } \mathrm{L} / \mathrm{g} \\ K_{L F} & \text { one-component Langmuir-Freundlich isotherm constant, } \mathrm{L} / \mathrm{mg} \\ K_{R P} & \text { one-component Redlich-Peterson isotherm constant, } \mathrm{L} / \mathrm{g} \\ K_{S} & \text { one-component Sips isotherm constant, } \mathrm{L} / \mathrm{mg} \\ K_{T} & \text { one-component Toth model constant, } \mathrm{L} / \mathrm{mg}\end{array}$


$K_{1 H} \quad$ Hill isotherm constant for $\mathrm{Cu}(\mathrm{II})$ in two-component mixture, mg/L

$K_{1 K C}$

$K_{I L F}$

$K_{I R P}$

$K_{1 S}$

$K_{I T}$

$K_{2 H}$

$K_{2 K C}$

$K_{2 L F}$

$K_{2 R P}$

$K_{2 S}$

$K_{2 T}$

m

N

$n_{H}$

$n_{K C}$

$n_{L F}$

$n_{R P}$

$n_{S}$

$n_{T}$

$n_{1 H}$

$n_{1 K C}$

$n_{1 L F}$

$n_{1 R P}$

$n_{1 S}$

$n_{1 T}$

$n_{2 H}$

$n_{2 K C}$

$n_{2 L F}$

$n_{2 R P}$

$n_{2 S}$

$n_{2 T}$

$q$

$q_{e}$

$q e 1$

$q_{e 2}$

$q_{m}$

$q_{m H}$

$q_{m L F}$

$q_{m S}$

$q_{m T}$

$q_{m 1 H}$

$q_{m I L F}$
Koble-Corrigan isotherm constant for $\mathrm{Cu}(\mathrm{II})$ in two-component mixture, $\mathrm{L} / \mathrm{g}$

Langmuir-Freundlich isotherm constant for $\mathrm{Cu}$ (II) in two-component mixture, $\mathrm{L} / \mathrm{mg}$

Redlich-Peterson isotherm constant for $\mathrm{Cu}$ (II) in two-component mixture, $\mathrm{L} / \mathrm{g}$

Sips isotherm constant for $\mathrm{Cu}(\mathrm{II})$ in two-component mixture, $\mathrm{L} / \mathrm{mg}$

Toth model constant for $\mathrm{Cu}(\mathrm{II})$ in two-component mixture, $\mathrm{L} / \mathrm{mg}$

Hill isotherm constant for $\mathrm{Zn}(\mathrm{II})$ in two-component mixture, $\mathrm{mg} / \mathrm{L}$

Koble-Corrigan isotherm constant for $\mathrm{Zn}$ (II) in two-component mixture, $\mathrm{L} / \mathrm{g}$

Langmuir-Freundlich isotherm constant for $\mathrm{Zn}$ (II) in two-component mixture, $\mathrm{L} / \mathrm{mg}$

Redlich-Peterson isotherm constant for $\mathrm{Zn}(\mathrm{II})$ in two-component mixture, $\mathrm{L} / \mathrm{g}$

Sips isotherm constant for $\mathrm{Zn}(\mathrm{II})$ in two-component mixture, $\mathrm{L} / \mathrm{mg}$

Toth model constant for $\mathrm{Zn}$ (II) in two-component mixture, $\mathrm{L} / \mathrm{mg}$

weight of the dry chitosan beads, $g$

number of data points

one-component sorbent heterogeneity constant of Hill isotherm

one-component sorbent heterogeneity constant of Koble-Corrigan isotherm

one-component sorbent heterogeneity constant of Langmuir-Freundlich isotherm

one-component sorbent heterogeneity constant of the Redlich-Peterson isotherm

one-component sorbent heterogeneity constant of Sips isotherm

one-component sorbent heterogeneity constant of Toth isotherm

sorbent heterogeneity constant of Hill isotherm for $\mathrm{Cu}(\mathrm{II})$ in two-component mixture

sorbent heterogeneity constant of Koble-Corrigan isotherm for $\mathrm{Cu}$ (II) in two-component mixture

sorbent heterogeneity constant of Langmuir-Freundlich isotherm for $\mathrm{Cu}(\mathrm{II})$ in twocomponent mixture

sorbent heterogeneity constant of the Redlich-Peterson isotherm for $\mathrm{Cu}(\mathrm{II})$ in twocomponent mixture

sorbent heterogeneity constant of Sips isotherm for $\mathrm{Cu}(\mathrm{II})$ in two-component mixture

sorbent heterogeneity constant of Toth isotherm for $\mathrm{Cu}$ (II) in two-component mixture

sorbent heterogeneity constant of Hill isotherm for $\mathrm{Zn}(\mathrm{II})$ in two-component mixture

sorbent heterogeneity constant of Koble-Corrigan isotherm for $\mathrm{Zn}$ (II) in two-component mixture

sorbent heterogeneity constant of Langmuir-Freundlich isotherm forZn(II) in twocomponent mixture

sorbent heterogeneity constant of the Redlich-Peterson isotherm for $\mathrm{Zn}(\mathrm{II})$ in twocomponent mixture

sorbent heterogeneity constant of Sips isotherm for $\mathrm{Zn}$ (II) in two-component mixture

sorbent heterogeneity constant of Toth isotherm for $\mathrm{Zn}$ (II) in two-component mixture

experimental sorption capacity on chitosan gel beads, $\mathrm{mg} / \mathrm{g}$

one-component equilibrium sorption capacity on chitosan gel beads, $\mathrm{mg} / \mathrm{g}$

$\mathrm{Cu}$ (II) ions equilibrium sorption capacity on chitosan gel beads in two-component mixture, $\mathrm{mg} / \mathrm{g}$

$\mathrm{Zn}$ (II) ions equilibrium sorption capacity on chitosan gel beads in two-component mixture, $\mathrm{mg} / \mathrm{g}$

component maximum adsorption capacity, $\mathrm{mg} / \mathrm{g}$

one-component Hill maximum adsorption capacity, $\mathrm{mg} / \mathrm{g}$

one-component Langmuir-Freundlich maximum adsorption capacity, $\mathrm{mg} / \mathrm{g}$

one-component Sips maximum adsorption capacity, $\mathrm{mg} / \mathrm{g}$

one-component Toth maximum adsorption capacity, $\mathrm{mg} / \mathrm{g}$

Hill maximum adsorption capacity of $\mathrm{Cu}(\mathrm{II})$ in two-component mixture, $\mathrm{mg} / \mathrm{g}$

Langmuir-Freundlich maximum adsorption capacity of $\mathrm{Cu}(\mathrm{II})$ in two-component mixture, $\mathrm{mg} / \mathrm{g}$ 


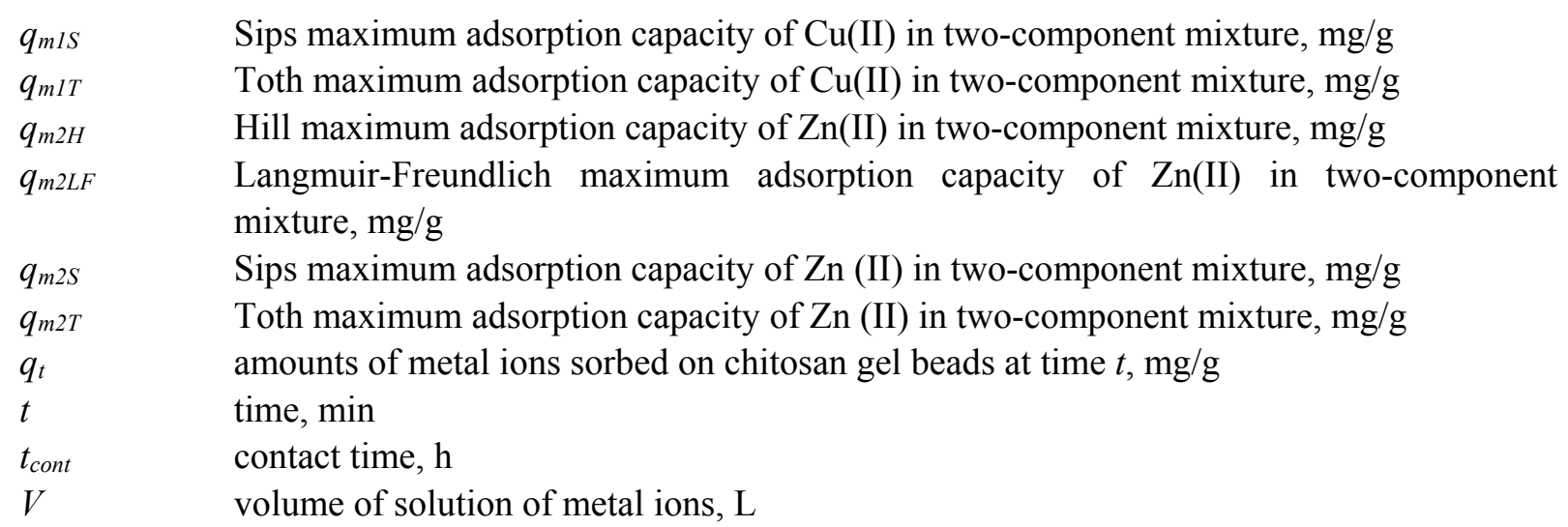

\section{Subscripts}

exp experimental

calc calculated

$i \quad$ first component in the particular two-component mixture

$j \quad$ second component in the particular two-component mixture

\section{REFERENCES}

Al-Asheh S., Banat F., Al-Omari R., Duvnjak Z., 2000. Predictions of binary sorption isotherms for the sorption of heavy metals by pine bark using single isotherm data. Chemosphere, 41, 59 - 665. DOI: 10.1016/S00456535(99)00497-X.

Alimohamadi M., Abolhamd G., Keshtkar A., 2005. $\mathrm{Pb}(\mathrm{II})$ and $\mathrm{Cu}(\mathrm{II})$ biosorption on Rhizopus arrhizus modeling mono- and multi-component systems. Miner. Eng., 18, 1325-1330. DOI: 10.1016/j.mineng.2005.08.007.

Allen S.J., Mckay G., Porter J.F., 2004. Adsorption isotherm models for basic dye adsorption by peat in single and binary component systems. J. Colloid Interf. Sci., 280, 322-333. DOI: 10.1016/j.jcis.2004.08.078.

Baran A., Biçak E., Baysal S.H., Önal S., 2006. Comparative studies on the adsorption of Cr(VI) ions on to various sorbents. Bioresource Technol., 98, 661-665. DOI: 10.1016/ j.biortech.2006.02.020.

Chen A.H., Liu S.C., Chen C.Y., Chen C.Y., 2008. Comparative adsorption of Cu(II), Zn(II) and Pb(II) ions in aqueous solution on the crosslinked chitosan with epichlorohydrin. J. Hazard. Mater., 154, 184-191. DOI: 10.1016/j.jhazmat.2007.10.009.

Chen C., 2013. Evaluation of equilibrium sorption isotherm equations. The Open Chem. Eng. J., 7, 24-44. DOI: 10.2174/1874123101307010024.

Corrigan T.E, Koble R.A., 1952. Adsorption isotherm for pure hydrocarbons. Ind. Eng. Chem., 44, $383-387$. DOI: 10.1021/ie50506a049.

Hamdaoui O., Naffrechoux E., 2007. Modeling of adsorption isotherms of phenol and chlorophenols onto granular activated carbon Part II. Models with more than two parameters. J. Hazard. Mater., 147, 401-411. DOI: 10.1016/j.jhazmat.2007.01.023.

Han R., Zhang J., Zou W., Shi H., Liu H., 2005. Equlibrium biosorption isotherm for lead ion on chaff. J. Hazard Mater., B125, 266-271. DOI: 10.1016/j.jhazmat.2005.05.031.

Hasan S., Ghosh T. K., Viswanath D. S, Boddu V. M., 2008. Dispersion of chitosan on perlite for enhancement of copper(II) adsorption capacity. J. Hazard. Mater., 152, 826-837. DOI: 10.1016/j.jhazmat.2007.07.078.

Ho Y. S., McKay G., 1999. Pseudo-second order model for sorption process. Process Biochem., 34, 451-465. DOI: 10.1016/S0032-9592(98)00112-5.

Jha I.N., Iyengar L., Prabhakara-Rao A.V.S., 1987. Removal of cadmium using chitosan. J. Environ. Eng., 114, 963-674. DOI: 10.1061/(ASCE)0733-9372(1988)114:4(962).

Jin L., Bai R., 2002. Mechanisms of lead adsorption on chitosan/PVA hydrogen beads. Langmuir, 18, 9765-9770. DOI: $10.1021 / 1 \mathrm{la0259171.}$

Kousalya G.N., Gandhi M. R., Meenakshi S., 2010. Sorption of chromium(VI) using modified forms of chitosan beads. Int. J. Biol. Macromol., 47, 308-315. DOI: 10.1016/ j.ijbiomac.2010.03.010. 
Kyzas G.Z., Bikiaris D.N., 2015. Recent modifications of chitosan for adsorption applications: A critical and systematic review. Marine Drugs, 13, 312-337. DOI: 10.3390/md13010312.

Lodeiro P., Cordero B., Barriada J.L., Herrero R., Sastre de Vincente M.E., 2005. Biosorption of cadmium by biomass of brown marine microalgae. Bioresource Technol., 96, 1796- 1803. DOI: 10.1016/j.biortech.2005.01.002.

Nastaj J., 2013. Modelowanie wybranych procesów adsorpcyjnych i biosorpcyjnych w ochronie środowiska. Bel Studio, Warszawa.

Norton L., Baskaran K., McKenzie T., 2004. Biosorption of zinc from aqueous solutions using biosolids. Adv. Environ. Res., 8, 629-635. DOI: 10.1016/S1093-0191(03)00035-2.

Onsosyen E., Skaugrud O., 1990. Metal recovery using chitosan. J. Chem. Technol. Biotechnol., 49, $395-404$. DOI: $10.1002 /$ jetb.280490410.

Osifo P.O., Webster A., van der Merwe H., Neomagus H.W., van der Gun M.A., Grant D.M., 2008. The influence of the degree of cross-linking on the adsorption properties of chitosan beads. Bioresource Technol., 99, 73777382. DOI: 10.1016/j.biortech.2008.01.053.

Oyrton A., Monteiro J., Airoldi C., 1999. Some thermodynamic data on copper- chitin and copper-chitosan biopolymer interactions. J. Colloid Interf. Sci., 212, 212-219. DOI: 10.1006/jcis. 1998.6063.

Qi N., 2003. Adsorption of organic compounds and water vapor on activated carbon: equilibria and fixed-bed humidity steps. PhD Thesis, University of Vanderbilt, Nashville.

Repo E., Warchoł J. K., Kurniawan T.A., 2010. Sillanpaa M. E.T., 2010. Adsorption of Co(II) and Ni(II) by EDTA- and/or DTPA- modified chitosan: Kinetic and equilibrium modeling. Chem. Eng. J., 161, 73-82. DOI: 10.1016/j.cej.2010.04.030.

Rinaudo M., 2006. Chitin and chitosan: Properties and applications. Prog. Polym. Sci., 31, 603-632. DOI: 10.1016/j.progpolymsci.2006.06.001.

Runping H., Wang Y., Hana P., Shi J., Yang J, Yongsen L., 2006. Removal of methylene bluefrom aqueous solution by chaff in batch mode. J. Hazard. Mater., B137, 550-557. DOI: 10.1016/j.jhazmat.2006.02.029.

Sankararamakrishnan N., Sharma A.K., Sanghi R., 2007. Novel chitosan derivative for the removal of cadmium in the presence of cyanide from electroplating wastewater. J. Hazard. Mater., 148, 353-359. DOI: 10.1016/j.jhazmat.2007.02.043.

Sulaymon A.H., Abbood D.W., Ali A.H., 2011. Competitive adsorption of phenol and lead from synthetic wastewater onto granular activated carbon. J. Environ. Sci. Eng., 5, 1389-1399.

Tomczak E., 2013. Water purification from heavy metal ions in a packed column. Sep. Sci. Technol., 48, 15, 2270-2276. DOI: 10.1080/01496395.2013.805224.

Veli S., B. Alyuz B., 2007. Adsorption of copper and zinc from aqueous solutions by using natural clay. J. Hazard. Mater., 149, 226-233. DOI: 10.1016/j.jhazmat.2007.04.109.

Vieira R.S., Guibal E., Silva E.A., Beppu M.M., 2007. Adsorption and desorption of binary mixtures of copper and mercury ions on natural and crosslinked chitosan membranes. Adsorption, 13, 603-611. DOI: 10.1007/s10450-007-9050-4.

Wan Ngah W.S., Ab Ghani S., Kamari A., 2005. Adsorption behaviour of Fe(II) and Fe(III) ions in aqueous solution on chitosan and cross-linked chitosan beads. Bioresour. Technol., 96, 443-450. DOI: 10.1016/j.biortech.2004.05.022.

Wan Ngah W.S, Fatinathan S., 2008. Adsorption of $\mathrm{Cu}(\mathrm{II})$ ions in aqueous solution using chitosan beads, chitosan-GLA beads and chitosan-alginate beads. Chem. Eng. J., 143, 1-3, 62-72. DOI: 10.1016/j.cej.2007.12.006.

Wang C., Liu J., Zhang Z., Wang B., Sun H., 2012. Adsorption of Cd(II), Ni(II) and Zn(II) by tourmaline at acidic conditions: Kinetic, thermodynamics and mechanism. Ind. Eng. Chem. Res., 51, 4397-4406. DOI: 10.1021/ie2023096.

Wang X., Du Y., Liu H., 2004. Preparation, characterization and antimicrobial activity of chitosan-Zn complex. Carbohyd. Polym., 56, 21-26. DOI: 10.1016/j.carbpol.2003.11.007.

Wu Z.B., Ni W.M., Guan B.H., 2008. Application of chitosan as flocculant for coprecipitation of Mn(II) and suspended solids from dual-alkali FGD regenerating process. J. Hazard. Mater., 152, 757-764. DOI: 10.1016/j.jhazmat.2007.07.042. 